\title{
Urban-Rural Difference in the Acceptance of Mass Health Examination in North-Eastern Japan
}

\author{
Masayuki Ineda, ${ }^{*}$, Haruo Nakatsuka, ${ }^{*}$ Takao \\ Watanabe, ${ }^{*}$ Shigeru Hisamichi, $\dagger$ Hiroyuki Shimizu, $\dagger$ \\ Susumu Fujisaku, $\ddagger$ Yoshimi Ichinowatari, $\S$ Jiro \\ Konno,§ Satoru Kuroda,§ Jiro Hirai, $\S$ Yasuo Ida, \\ Seiki Suda// and Kunio Kato// \\ *Departments of Environmental Health, †Public Health, \\ and $\ddagger$ Hospital and Medical Care Administration, Tohoku \\ University School of Medicine, Sendai 980, §Department of \\ Health and Environment, Miyagi Prefecture, Sendai 980, \\ //Department of Health, Sendai City, Sendai 980, and \\ "Department of Public Health, Kyoto University Faculty \\ of Medicine, Kyoto 606
}

Imeda, M., Nakatsuka, H., Watanabe, T., Hisamichi, S., Shimizu, H., Fujisaku, S., Ichinowatari, Y., Konno, J., Kuroda, S., Hirai, J., Ida, Y., Suda, S. and Kato, K. Urban-Rural Difference in the Acceptance of Mass Health Examination in North-Eastern Japan. Tohoku J. Exp. Med., 1989, 158 (1), 57-72 Over 40000 residents ( $\leq 40$ years of age) in a city (Sendai ; the city group), a town (Shiroishi; the town group) and two villages (Wakuya and Tajiri; the village group) in Miyagi prefecture in north-eastern Japan responded in a questionnaire survey on their attitude towards mass health examinations (i.e., whether they underwent in the previous year and if so where) on 4 items of blood pressure measurement, chest $\mathrm{x}$-ray examination and screening tests for stomach and cervical cancer. The coverage rates were about $70 \%$ on an average both for blood pressure measurement and for chest $\mathrm{x}$-ray examination, whereas the rates for cancer screening were between $30-40 \%$. As for the opportunity of the former two examinations, the workplace mass examination played a large role in the case of the city and town groups (especially among men but not women) in addition to visit to clinics, in contrast to the case of the village group in which people depended much on regional mass examination service. The trend was essentially reproducible in stomach cancer screening although the over-all coverage rate was low, whereas women in the three groups almost exclusively utilized clinics for cervical cancer screening with one exception that the mobile unit service appeared to be equally accepted in the village group. cervical cancer ; chest disease ; hyperten-

sion; mass health examination; stomach cancer

Received March 14, 1989 ; revision accepted for publication May 10, 1989.

Requests for reprints to: Prof. Masayuki Ikeda, Department of Public Health, Kyoto University Faculty of Medicine, Kyoto 606, Japan. 
Statistics are available to show that how many people and therefore how many percentage of the residents participate in a particular mass health examination, e.g. local health authority-organized blood pressure measurement, in a region of concern (e.g., Miyagi prefecture 1985a, b). The chance for blood pressure measurement for the individual is, however, not necessarily limited to the examination offered by the authorities; the subject may consult his/her family doctor for the check, or he/she may be examined at the routine check-up in the workplace in case he/she serves in a governmental organization or in a large company (Ministry of Health and Welfare 1974). The information, as far as it is correct, should be equally valuable for the health maintenance of him- or herself regardless of variation in chance of the measurement. The critical point then is whether or not such service is offered, the examination is made and the information is available. No survey appears to be made to investigate the attitude of the individual residents in the acceptance of various mass health examination. The present study was conducted as a part of multifaceted "Health and Environment" program in Miyagi prefecture to investigate how the residents in Miyagi prefecture access health examination for their health maintenance and if there is any urban-rural difference in the response.

\section{Materials and Methods}

\section{Study populations}

The study method was previously described in detail (Ikeda et al. 1986; Nakatsuka et al. 1988; Sato et al. 1989). In brief, all inhabitants at the ages of $\geq 40$ years in 6 primary school sectors in the center of the city of Sendai (to be called the city group), in a central part of the city of Shiroishi (the town group), and in two entire farming villages of Wakuya and Tajiri (neighboring to each other and combined to form the village group) were examined if and where they underwent health examination in the preceding year. The survey was made by means of the self-completion questionnaires, which consisted of questions on various facets of life such as current subjective symptoms, medical history, dietary habits, etc., and the part on the acceptance of mass health examination (as to be detailed in the succeeding section) is analyzed in the present study. The findings on health effects of air pollution (Ikeda et al. 1986) and on food habits (Nakatsuka et al. 1988; Sato et al. 1989) in Sendai, Wakuya and Tajiri have been reported. The survey in Sendai, Wakuya and Tajiri was conducted in February, 1984, and that in Shiroishi in February, 1988. The numbers of examinees, respondents and response rates are summarized in Table 1.

The characteristics of the three study regions (for locations, see Fig. 1) are summarized as follows (Kahoku Shimpo 1982) ; Sendai with a population of about 800,000 is a prefectural city and a center of administration, business, transportation, university/college level education, and other social activities. Shiroishi with ca. 41,000 residents is a regional center of administration and education (up to high school levels) with spinning and other light industries in addition to horticulture for peach and persimmon. Wakuya and Tajiri with 21,000 and 15,000 inhabitants, respectively, have been predominantly agricultural in economy with rice as staple.

\section{Questionnaires}

The self-completion questionnaires had 30 questions on various facets of life, and 


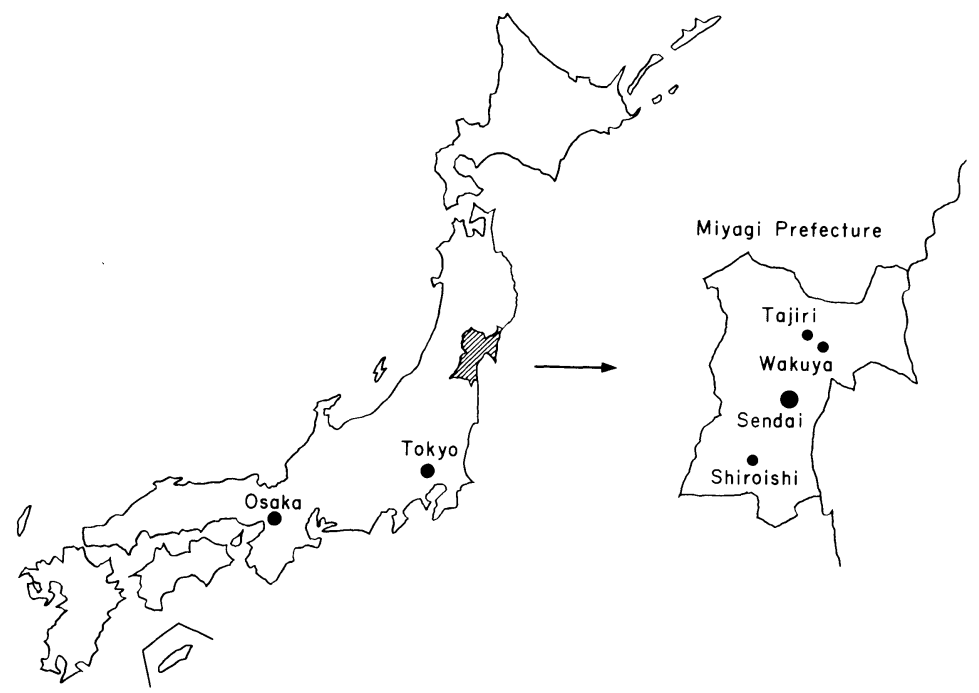

Fig. 1. Location of three study regions in Miyagi prefecture, Japan. The shaded area indicates Miyagi prefecture, and three dots in the expanded map of Miyagi prefecture are for Sendai, Shiroishi, Wakuya and Tajiri, respectively.

included following 7 questions on the response of the examinees towards mass health examinations for hypertension, tuberculosis, and stomach/(uterine) cervical cancer. The questionnaires were hand-delivered and hand-collected by local volunteer organizations with due care to protect privacy of each respondent (Ikeda et al. 1986; Nakatsuka et al. 1988). The seven questions analyzed in this article were as follows:

Question 1: Have you ever engaged in the following activities? (Identify all among the followings by circle.)

A. Yes, I do (or did).

1. Agriculture.

2. Forestry.

3. Mining.

B. No, I do (did) not.

Question 2: What type of health (social) insurance do you have as either an insured individual or as a family dependent? (Specify by circle.)

1. National health insurance.

2. Social insurance by mutual aid associations.

3. Government-managed health insurance.

4. Society-managed health insurance.

5. Others (Specify by writing).

[Note: All Japanese nationals are covered by one of the health (social) insurance systems cited above. The employees (as insured) and their family dependents of large companies are covered by society-managed health insurance, whereas those in medium or small companies (and their family dependents) are by government-managed one. Employees of the central and local governments, public enterprise corporations and school teachers, separately, form mutual aid associations for various social insurance (i.e., social insurance by mutual aid associations which includes health insurance). Other people (e.g., those in small-scale independent business and farmers) regionally organize a national health insurance system. For details of the insurance system, see Ministry of Health and 
Welfare (1974).

Additional question: Are you the insured or a family dependent? (Specify by circle).

1. The insured.

2. The family dependent.

Question 3: Did you undergo blood pressure measurement last year? If yes, where? (Identify all among the followings by circle.)

A. Yes, I did.

1. At the regional mass health examination organized by local health authorities.

2. At the mass medical examination in the workplace.

3. At the clinical facilities (e.g., hospitals, dispensaries, or out-patient clinics, excluding the health center).

4. At the regional health center.

5. Others (Specify by writing.)

B. No, I did not.

Question 4 : Did you undergo chest x-ray examination (for tuberculosis) last year ? If yes, where? (Identify all among the followings by circle.)

A. Yes, I did.

1. At the regional mass health examination organized by local health authorities.

2. At the regional health center.

3. At the mass medical examination in the workplace.

4. At the clinical facilities (e.g., hospitals, dispensaries, or out-patient clinics, excluding the health center).

5. Others (Specify by writing.)

B. No, I did not.

Question 5: Did you undergo stomach cancer screening last year? If yes, where? (Identify all among the followings by circles.)

A. Yes, I did.

1. At the regional mass health examination organized by local health authorities.

2. At the mass medical examination in the workplace.

3. At the clinical facilities (e.g., hospitals, dispensaries, or out-patient clinics, excluding the health center).

4. Others (Specify by writing.)

B. No, I did not.

(Note: No medical service of GI tract check-up was available in the regional health center.)

Question 6: How often did you have mass screening for stomach cancer in these 5 years? Give the number.

Question 7 (Women only) : Did you undergo screening for cervical cancer last year? If yes, where? (Identify all among the followings by circle.)

A. Yes, I did.

1. At the mass medical examination in the workplace.

2. At the clinical facilities (e.g., hospitals, dispensaries, or out-patient clinics, excluding the health center).

3. By a cancer screening mobile unit.

4. Others (Specify by writing.)

B. No, I did not.

\section{Statistical analyses}

Basic statistics were conducted with an ACOS 1000 system in the Tohoku University Computer Center utilizing a package program "CROSS". The significance of difference between the groups was examined by $t$-test, chi-square test or analysis of variance as indicated. 


\section{RESUlts}

\section{Response rates and age distribution}

In total, over 40000 people responded to the questions with a grand response rate of $87.7 \%$ (Table 1). The number of the respondents was largest in the city group (i.e., in Sendai) in both sexes, slightly smaller in the village group (i.e., in Wakuya + Tajiri) and about half the size of the former two in the town group (i.e., in Shiroishi). The respondent numbers were essentially equal between the two sexes in the three regions studied. It was found that the difference in age distribution was small if present among the three study groups (Table 1) when the age structure was compared, and accordingly, no adjustment for age was made in the following analyses.

\section{Characteristics of the study population}

The comparison of work history of the respondents in primary industries made it clear that the rate of those who once engaged in agriculture was markedly

TABLE 1. Number of respondents in the three study regions, by sex and age

\begin{tabular}{|c|c|c|c|c|c|}
\hline & \multirow{2}{*}{ Sex and age range } & \multicolumn{4}{|c|}{ Region* } \\
\hline & & City & Town & Village & Total \\
\hline \multirow[t]{6}{*}{ Men } & Number of respondents & 7703 & 3707 & 6680 & 18090 \\
\hline & $40-49$ years & $30.1 \%$ & $27.5 \%$ & $27.5 \%$ & $28.6 \%$ \\
\hline & $50-59$ years & $30.2 \%$ & $29.1 \%$ & $33.9 \%$ & $31.3 \%$ \\
\hline & $60-69$ years & $20.9 \%$ & $22.7 \%$ & $20.3 \%$ & $21.0 \%$ \\
\hline & 70 years and over & $15.9 \%$ & $17.6 \%$ & $14.9 \%$ & $15.9 \%$ \\
\hline & Unknown & $2.9 \%$ & $3.1 \%$ & $3.4 \%$ & $3.2 \%$ \\
\hline \multirow[t]{6}{*}{ Women } & Number of respondents & 9693 & 4382 & $\cdot 8048$ & 22123 \\
\hline & 40-49 years & $28.9 \%$ & $24.1 \%$ & $25.1 \%$ & $26.6 \%$ \\
\hline & $50-59$ years & $29.9 \%$ & $28.6 \%$ & $31.6 \%$ & $30.3 \%$ \\
\hline & $60-69$ years & $22.0 \%$ & $24.9 \%$ & $21.5 \%$ & $22.4 \%$ \\
\hline & 70 years and over & $16.2 \%$ & $19.1 \%$ & $18.1 \%$ & $17.5 \%$ \\
\hline & Unknown & $3.0 \%$ & $3.3 \%$ & $3.7 \%$ & $3.2 \%$ \\
\hline \multirow[t]{7}{*}{ Total } & Number of respondents & 17396 & 8089 & 14728 & 40213 \\
\hline & (Response rate $\dagger$ ) & $(81.4 \%)$ & $(91.8 \%)$ & $(94.1 \%)$ & $(87.7 \%)$ \\
\hline & 49-49 years & $29.4 \%$ & $25.7 \%$ & $26.2 \%$ & $27.5 \%$ \\
\hline & $50-59$ years & $30.0 \%$ & $28.8 \%$ & $32.7 \%$ & $30.7 \%$ \\
\hline & $60-69$ years & $21.5 \%$ & $23.9 \%$ & $21.0 \%$ & $21.8 \%$ \\
\hline & 70 years and over & $16.1 \%$ & $18.4 \%$ & $16.6 \%$ & $16.8 \%$ \\
\hline & Unknown & $3.0 \%$ & $3.2 \%$ & $3.5 \%$ & $3.2 \%$ \\
\hline
\end{tabular}

*Unless otherwise specified, the values in the table are the percentages taking the number of respondents as 100 .

$\dagger$ The response rate is defined as [respondents/examinees] $\times 100(\%)$. 
TABLE 2. History of engagement in primary industries

\begin{tabular}{clrrrr}
\hline Sex & Industry* & City & Town & Village & Total \\
\hline \multirow{2}{*}{ Men } & Agriculture & $7.2 \%$ & $22.3 \%$ & $53.1 \%$ & $27.3 \%$ \\
& Forestry & $1.3 \%$ & $5.6 \%$ & $9.1 \%$ & $5.1 \%$ \\
\multirow{3}{*}{ Women } & Mining & $1.5 \%$ & $2.2 \%$ & $2.7 \%$ & $2.1 \%$ \\
& Agriculture & $5.8 \%$ & $15.4 \%$ & $43.1 \%$ & $21.3 \%$ \\
& Forestry & $0.6 \%$ & $1.9 \%$ & $2.8 \%$ & $1.6 \%$ \\
& Mining & $0.2 \%$ & $0.3 \%$ & $0.4 \%$ & $0.3 \%$ \\
\hline
\end{tabular}

*There was no fishing activity in the three regions.

different among the three groups; the rate was highest in the village group, followed by the town group and lowest in the city group both in men and in women (Table 2) as expected. The rate of current farmers or ex-farmers among men was almost 8 times higher in the village group than in the city group. A similar difference was observed in forestry and to a lesser extent in mining, but the numbers of the people with experiences in the latter two industries were very limited in any of the three groups. Very few fishing activity was present in the study regions.

The study populations were further examined for types of the health (social) insurance the individuals were covered by (Table 3 ). It was apparent from the table that the rate of those covered by national health insurance is highest in the village group, then in the town group and the lowest in the city group; the

TABLE 3. The types of health insurance among the respondents

\begin{tabular}{|c|c|c|c|c|c|c|c|c|}
\hline \multirow{2}{*}{ Insurance } & \multicolumn{4}{|c|}{ Men } & \multicolumn{4}{|c|}{ Women } \\
\hline & City & Town & Village & Total & City & Town & Village & Total \\
\hline \multicolumn{9}{|l|}{ Type of insurance (HI or SI*) } \\
\hline National HI & $40.2 \%$ & $45.2 \%$ & $69.4 \%$ & $52.0 \%$ & $44.7 \%$ & $45.7 \%$ & $66.6 \%$ & $52.9 \%$ \\
\hline $\begin{array}{l}\text { SI by mutual aid } \\
\text { associations }\end{array}$ & $13.6 \%$ & $14.0 \%$ & $7.6 \%$ & $11.5 \%$ & $12.7 \%$ & $11.7 \%$ & $6.7 \%$ & $11.2 \%$ \\
\hline Government-managed $\mathrm{HI}$ & $26.9 \%$ & $22.6 \%$ & $13.7 \%$ & $21.1 \%$ & $25.1 \%$ & $24.1 \%$ & $15.5 \%$ & $21.4 \%$ \\
\hline Society-managed HI & $15.2 \%$ & $10.7 \%$ & $4.3 \%$ & $10.3 \%$ & $12.2 \%$ & $9.1 \%$ & $5.0 \%$ & $9.0 \%$ \\
\hline Others plus no marking & $4.1 \%$ & $7.5 \%$ & $5.0 \%$ & $5.1 \%$ & $5.3 \%$ & $9.4 \%$ & $8.6 \%$ & $6.5 \%$ \\
\hline \multicolumn{9}{|c|}{ The insured or a family dependent } \\
\hline The insured & $84.2 \%$ & $73.5 \%$ & $64.0 \%$ & $74.6 \%$ & $29.9 \%$ & $32.4 \%$ & $19.5 \%$ & $26.6 \%$ \\
\hline A family dependent & $7.7 \%$ & $15.0 \%$ & $20.7 \%$ & $14.0 \%$ & $61.7 \%$ & $55.6 \%$ & $64.4 \%$ & $61.5 \%$ \\
\hline No answer & $8.1 \%$ & $11.6 \%$ & $15.4 \%$ & $11.5 \%$ & $8.4 \%$ & $12.1 \%$ & $16.1 \%$ & $11.9 \%$ \\
\hline
\end{tabular}

For total number of the respondents, see Table 1.

${ }^{*} \mathrm{HI}$ for health insurance; SI for social insurance. 
difference is statistically significant $(p<0.01)$ both in men and in women. A mirror image was the case for society-managed health insurance. The rates are similar between the two sexes in the three groups independent of the types of insurance systems; e.g., $40.2 \%$ of the men in the city group are covered by the national health insurance, and the rate is $44.7 \%$ in the women of the same group. Men themselves were mostly the insured, whereas a majority of women was covered as a family dependent regardless of either different types of the insurance or the place of the residence (Table 3 ).

\section{Coverage of health examination for hypertension and chest disease}

Men and women in the three study regions were classified depending on the health examinations they had for early detection of two manageable diseases of hypertension and tuberculosis. In the case of blood pressure measurement (the upper half in Table 4 ), about $70 \%$ or more of the respondents underwent the examination in the previous year independent of the location of the residence. The rate was highest for the consultation at the clinical facilities in both sexes followed by the rate for workplace examination among men (but not among women) in the city group, whereas almost $50 \%$ of the people in the village group were examined at the regional mass examination organized by the local health authorities. In the town group, the rates of men who had examined at regional or workplace mass examination and of women examined at workplace mass examination were just between the values for the city and village groups. Such different attitude on acceptance of various occasions for health examination was essentially reproducible when the cases of chest $x$-ray examination were analyzed (the lower half in Table 4), with an exception that the rates of those who had examination in the previous year were not similar among the three groups; it was higher in the town and village groups and lower in the city group. The dependency of men and women in the village group on the regional mass examination was, however, even more evident (i.e., $64 \%$ in men and $80 \%$ in women) in the case of chest $\mathrm{x}$-ray examination.

\section{Limited acceptance of cencer screening}

When similar analyses were made for men and women in case of stomach cancer examination and for women in case of cervical cancer examination, it was shown (Table 5) that the acceptance of cancer screening examination appeared to be low, i.e., $46 \%$ at best (stomach cancer test among men in the town group) and less than one third in most of other instances, making a contrast to the case of blood pressure measurement which was widely accepted (Table 4). Among those who underwent the examination in the previous year (although they were small in number), the two leading occasions for stomach cancer screening in the city group were visit to clinics and workplace examination for men, whereas clinics played even a bigger role for women. In contrast, both men and women in the 


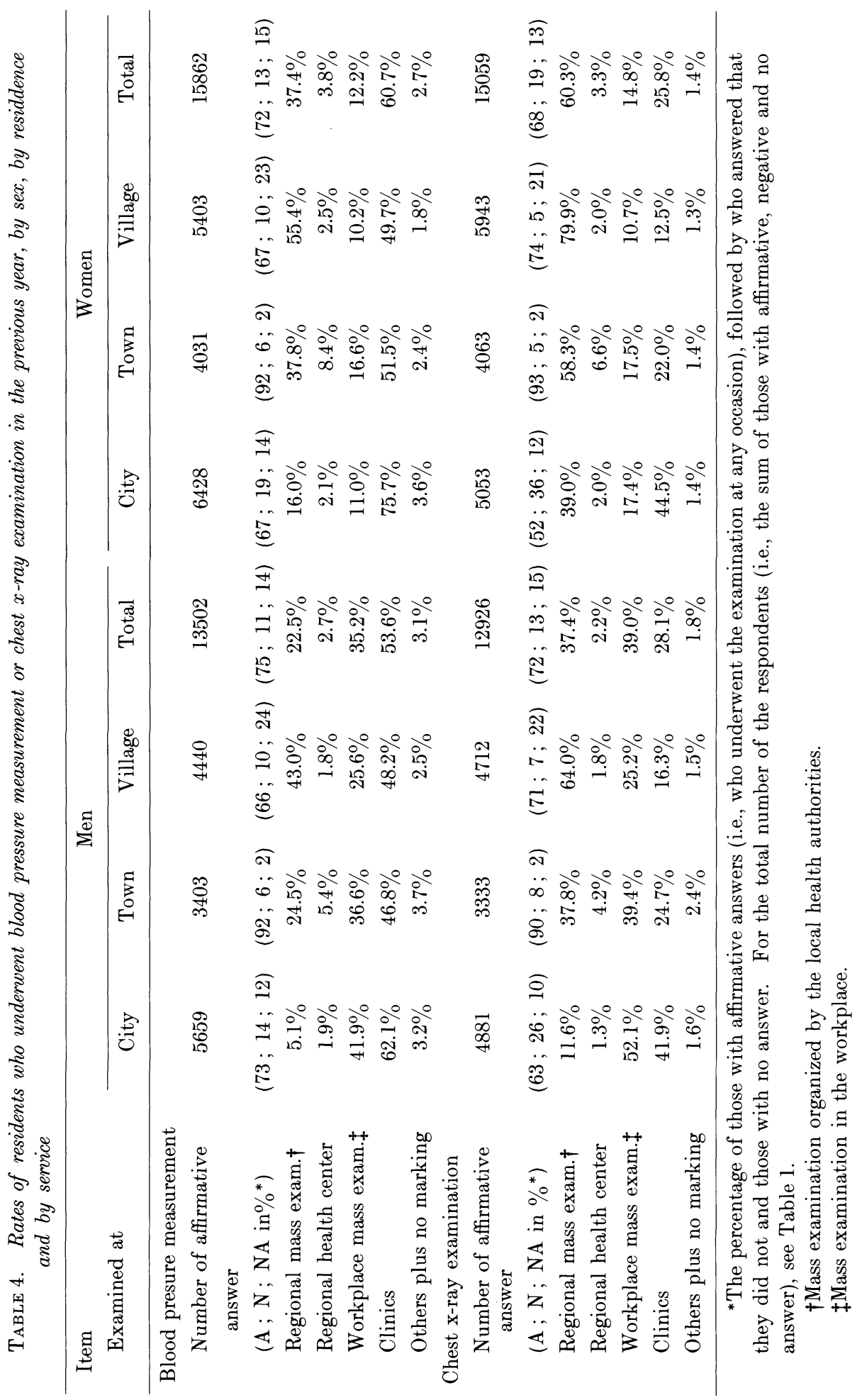


Urban-Rural Difference in Mass Examination

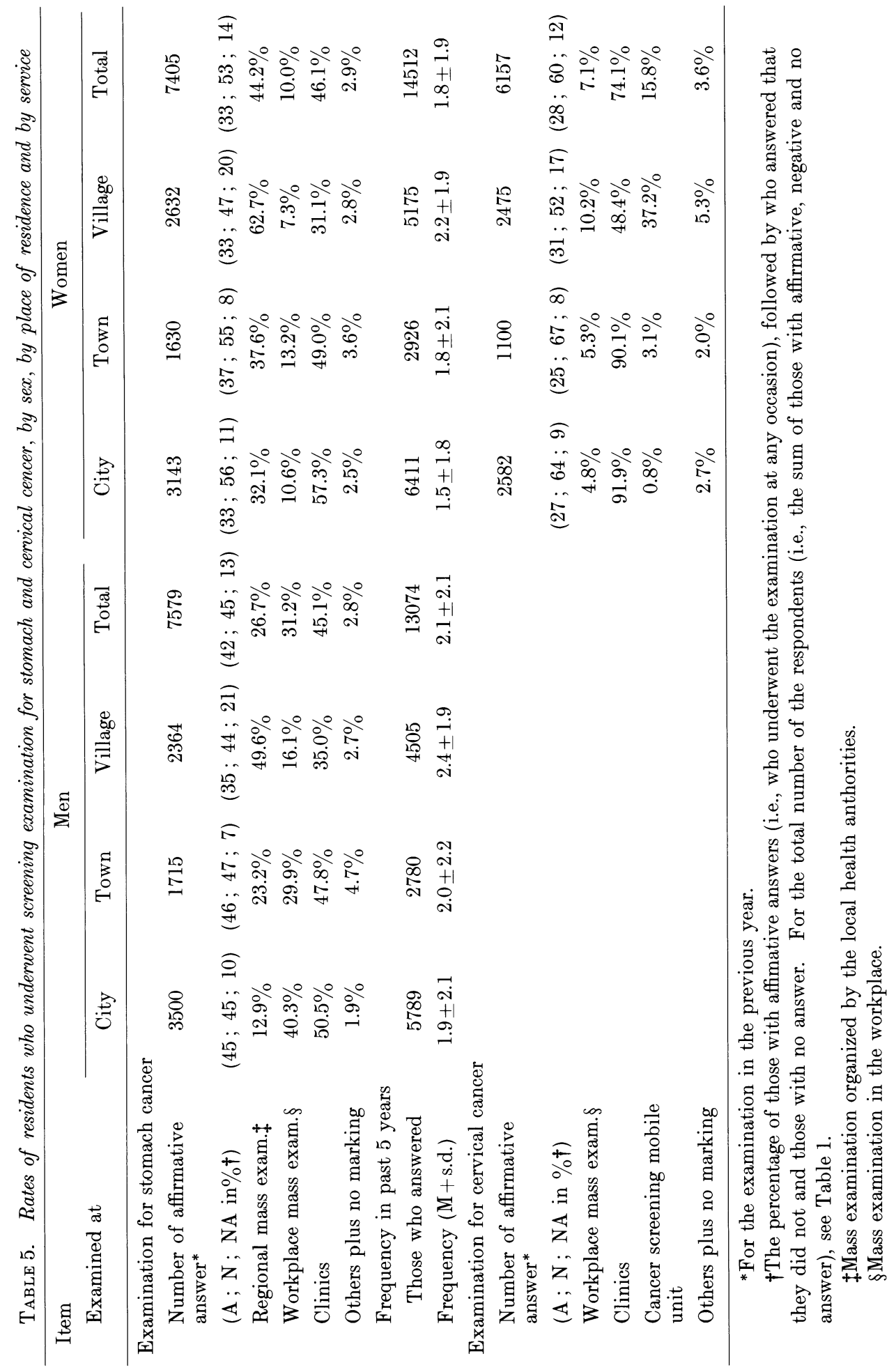


village group applied for the regional mass examination more extensively than the people in the city for the cancer screening. In the town group, visit to clinics was the most common for both men and women, followed by workplace examination in men and regional mass examination in women.

The coverage rate was even lower in the case of cervical cancer screening, i.e., from $25 \%$ for town women to $31 \%$ for village women. As for the occasion of examination, women in the city and the town groups almost exclusively relied upon clinical facilities, whereas women in the village used both clinics and to a slightly lesser extent, the cancer screening mobile unit.

\section{Discussion}

The present questionnaire survey has clearly demonstrated that more than a half of the residents in the three study regions in Miyagi prefecture used to have blood pressure measurement and chest x-ray examination every year (Table 4), whereas the coverage rates of the screening for serious diseases like stomach and cervical cancer are lower at the level of well below $50 \%$ (Table 5 ). The behavior of the people in utilizing the opportunity of health examination varied depending not only on the place of residence (i.e., urban-rural difference in acceptance) and on the sex, but acceptability of the examination (e.g., blood pressure measurement is easy to accept) as well as the seriousness of the disease [e.g., more people are willing to undergo examination for more manageable diseases like hypertension and lung tuberculosis (i.e., 60-70\%) than for more insidious diseases such as cancer $(30-40 \%$ ) (Table 4 and Table 5)]. For the examination of the former two diseases, men in the city mostly take advantage of mass examination in the workplaces and also consultation in clinical facilities, and women in the city depend more on visit to clinics, whereas men and women in rural areas use health authority-organized mass screening examination (Table 4); it is apparent that women are employed in the secondary or tertiary industries less than men even in the city group (Table 2 ) and therefore chance of health examination in workplace is less available to women. In this connection, it should be noted that medical doctors and hospital beds are more available in the city than in the town, and least so in the villages among the three regions examined (Table 6), even though the numbers of visit to clinics and hospitalization did not differ very much suggesting that the needs for medical care may be essentially equal among the three groups.

Of particular interest is the difference of the values in Tables 4 and 5 from the screening rates in Table 6 . The comparison shows that the real coverage rates for many health examinations are in fact higher than the rates usually understood. For example, the coverage rates for general health examination under Senior Health Act is 14-23\% (depending on the year) in Sendai (man and women combined; Table 6 ), but $73 \%$ of men and $67 \%$ of women had blood pressure measurement, and $63 \%$ of men and $52 \%$ of women had chest $x$-ray examination (Table 4). Similarly, the official figure for stomach cancer screening rate in 
Urban-Rural Difference in Mass Examination

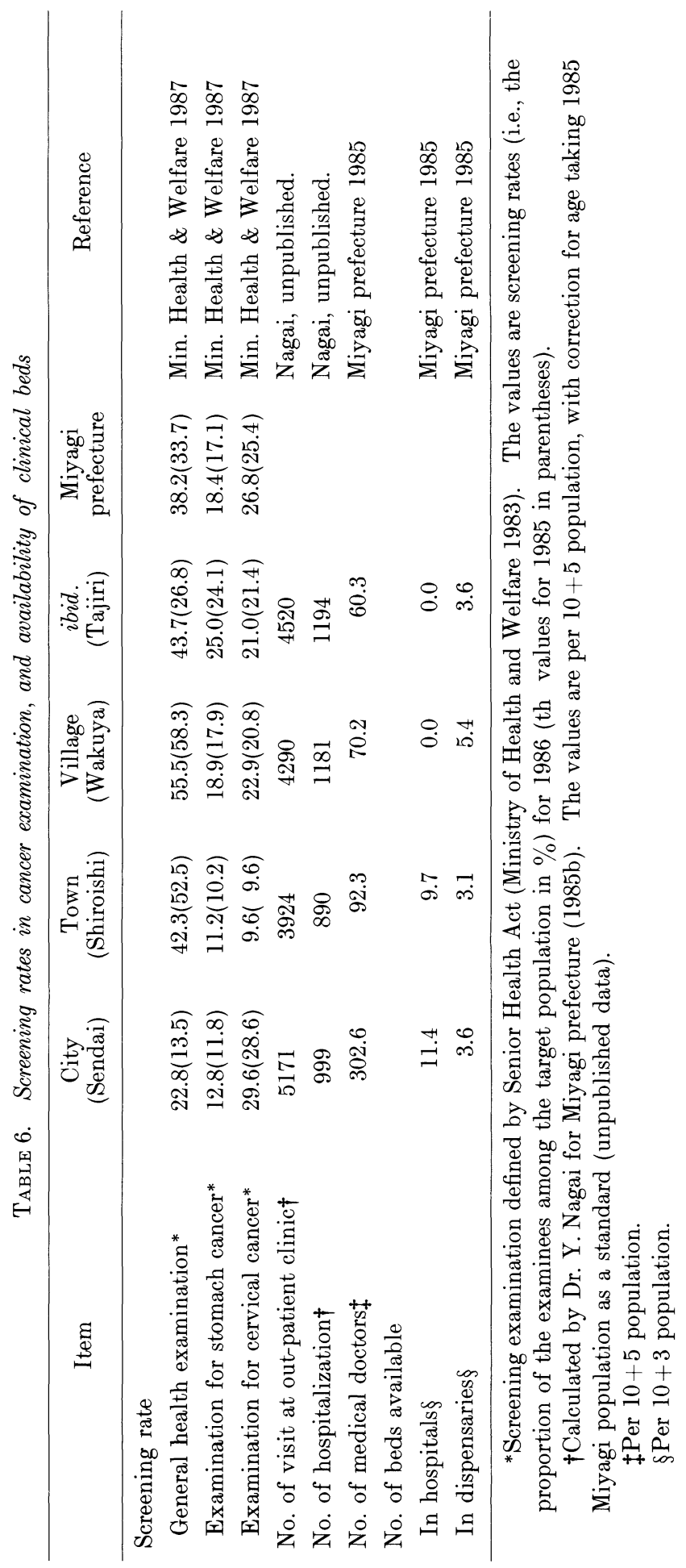


M. Ikeda et al.

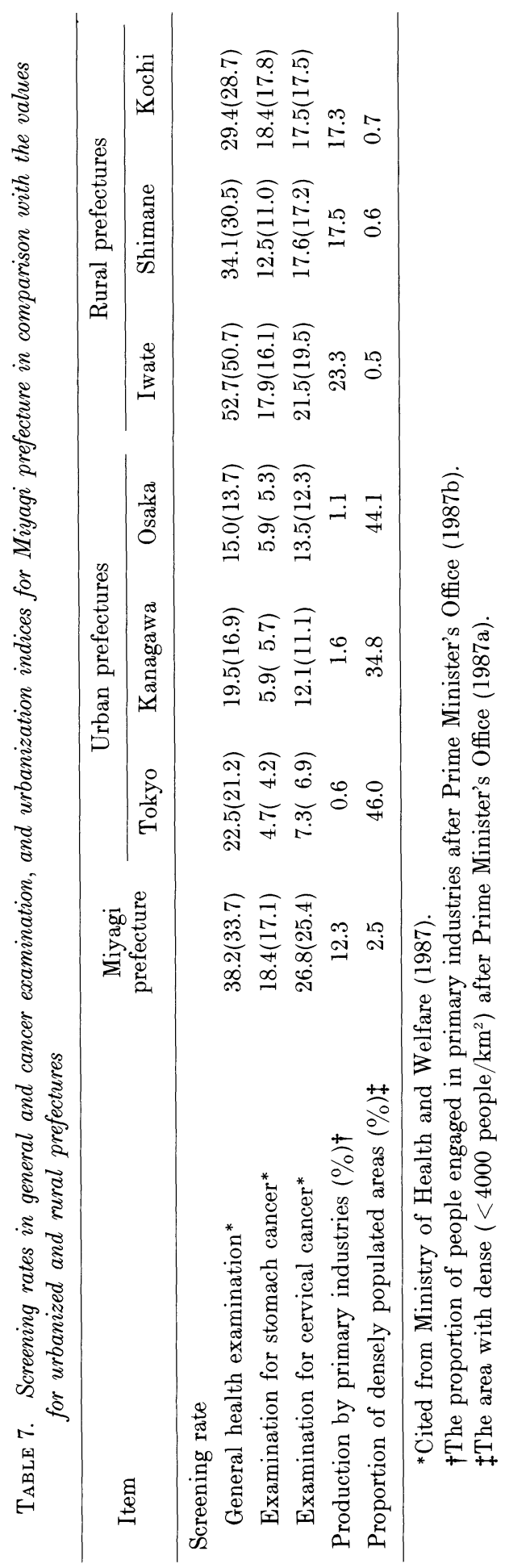


Sendai (man and women combined) is $12-13 \%$ (Table 6 ) whereas $45 \%$ of men and $33 \%$ of women were examined for stomach cancer there (Table 5). The major reason for the difference is that the rates in Tables 4 and 5 take not only the regional mass health examination but other examinations such as workplace mass examinations and personal visits to clinics. Currently, possible association between the acceptance of various health examinations and type of health insurance (which probably varies among the three study regions) in under study, and will be reported separately.

Better acceptance of mass examination in rural areas than in urban areas is in agreement with previous publication. For example, it was reported that the screening rates in general examination as well as the rates in the screening for stomach and cervical cancer were all higher in the two villages of Wakuya and Tajiri and lower in the city of Sendai both in 1983 and 1984 (Ministry of Health and Welfare 1987). On prefectural basis, it is also true that the rates were generally lower in urban prefectures like Tokyo (with low proportion for primary industries and high density of population) and higher in rural areas like Iwate prefecture (where the primary industries are predominant and the population density is low) (Table 7). In this regard, the study populations in the city of Sendai and in the villages of Wakuya and Tajiri are apparently most and least urbanized among the three study regions (Table 2), and the prefecture of Miyagi should be considered between the two extreme groups of prefectures (Table 7) in a whole country with an employment rate in primary industries (value for agriculture in parenthesis) of $9.3 \%(8.3 \%)$ in 1985 . The corresponding values for whole Japan are $14.6 \%$ and $12.2 \%$, respectively (Prime Minister's Office 1987a). It is criticized that the definition of the screening rate is not always followed in practice, inevitably making the quality of the screening rates thus calculated (and cited in Table 6 and 7) rather poor for interregional comparison (Amagami 1987). The difference observed is however apparently large enough to overcome such difficulties.

Particular attention should be paid to the relatively poor acceptance by the study populations of screening examination for two insidious serious diseases of stomach and cervical cancer. The service of the two screening programs, especially that of cervical cancer screening, have been questioned recently (Bailar and Smith 1986; Murphy et al. 1987; Schnieden 1988) because, e.g., the rates of mortality from cervical cancer have not fallen in Britain (Schnieden 1988) and cost-benefit balance should also be taken into account (Morrissey 1982 ; Schnieden 1988). The majority of the opinions is, however, in the favor of the validity of the screening and continuation of the service both for stomach (Okui and Tejima 1980 ; Shanmugaratnam 1985 ; Shiratori et al. 1985 ; Arisue et al. 1986 ; Hisamichi et al. 1988) and cervical cancer detection (Arisue et al. 1986; Battista and Grover 1988; van der Graaf et al. 1988). The experiences by Anderson et al. (1988) and MacCormac et al. (1988) that women of younger ages, e.g., 20-30 years 
or 25-34 years have higher risk of in-situ cervical cancer suggest the extension of cervical cytology service towards the women of lower ages.

Given that screening for chest disease, hypertension (Canadian Task Force for the Periodic Health Examination 1979) and cancer of stomach and cervix is all valid and beneficial, it is apparently worth to discuss the factors disturbing wider acceptance of the service. Based on a national survey in the United States on cervical and breast cancer, Hayward et al. (1988) found that the cervical smear test is less frequently received by the women of older ages (e.g., over 65 years), and that those who has no insurance or of low socio-economic status are less likely to have tests. Similarly, Akamatsu et al. (1986a) observed in a questionnaire survey on stomach cancer screening that the screening rate was high among company employees who have workplace examination in agreement with the observation in the present study (Table 5), whereas the rate was low among housewives who primarily depend on regional examination for health check. High attendance rates were observed when cervical screening tests were introduced to workplaces, suggesting potential contribution of workplace-based screening for cancer of cervix also (Morris 1988; Reid 1988). Further analysis in the reason of not to receive an examination (Akamatsu et al. 1988b) revealed that "inconvenience" or difficulty in the access due, e.g. to shortage of time, far location of the examination site, etc. was the leading reason why they were not examined. While this observation may suggest the need for the improvement of the service system so that the people will have easier access, it appears apparently too premature to draw any solid conclusion because "inconvenience" would well be a general excuse for varieties of hidden reasons.

\section{Acknowledgments}

Thanks are due to Dr. Y. Nagai of Department of Hospital and Medical Care Administration, Tohoku University School of Medicine, Sendai 980, for his generous supply of unpublished data.

\section{References}

1) Akamatsu, N., Ide, M., Ueda, Y., Kondo, Y., Nakamura, S., Mori, T., Ogimoto, I. \& Yoshimura, T. (1986a) A population survey on mass screening program for gastric cancer. Part 1. Population characteristics related to examination rates for screening program. J. Univ. Occup. Environm. Health, 8, 177-183. (Japanese)

2) Akamatsu, N., Ide, M., Ueda, Y., Kondo, Y., Nakamura, S., Mori, T., Ogimoto, I. \& Yoshimura, T. (1986b) A population survey on mass screening program for gastric cancer. Part 2. Why don't they receive mass screening examination? J. Univ. Occup. Environm. Health, 8, 415-422. (Japanese)

3) Amagami, Y. (1987) Fundamental study on effective administration of examination for secondary cancer prevention. Report to Ministry of Health and Welfare, the Government of Japan.

4) Anderson, G.H., Boyes, D.A., Benedet, J.L., Le Riche, J.C., Matisic, J.P., Suen, K.C., Worth, A.J., Millner, A. \& Bennnett, O.M. (1988) Organization and results of cervical cytology screening programme in British Columbia, 1955-85. Br. Med. J., 
296, $975-978$.

5) Arisue, T., Tamura, K., Yosida, Y., Tebayasi, A., Yamaguchi, Y., Ikeda, S. \& Ohtuka, S. (1986) Comparison of the changes in the mortality from stomach cancer between the model areas of mass screening for stomach cancer and the control areas. $J$. Gastroenterol. Mass Surv. (Nippon Shokaki Shudan Kenshin Shi), 73, 26-32. (Japanese)

6) Bailar, J.C., III \& Smith, E.M. (1986) Progress against cancer? N. Engl. J. Med., 314, 1226-1232.

7) Battista, R.N. \& Grover, S.A. (1988) Early detection of cancer; an overview. Annu. Rev. Public Health, 9, 21-45.

8) Canadian Task Force on the Periodic Health Examination (1979) The periodic health examination. Can. Med. Assoc. J., 121, 1193-1254.

9) Hayward, R.A., Shapiro, M.F., Freeman, H.E. \& Corey, C.R. (1988) Who gets screened for cervical and breast cancer? Results of a new national survey. Arch. Intern. Med., 148, 1177-1181.

10) Hisamichi, S., Sugawara, N. \& Fukao, A. (1988) Effectiveness of gastric mass screening in Japan. Cancer Detect. Prev., 11, 322-329.

11) Ikeda, M., Watanabe, T., Watanabe, T., Hisamichi, S., Shimizu, H., Fijisaku, S., Ichinowatari, Y., Ida, Y., Suda, M., Kato, K. \& Ikeda, M. (1986) Upper respiratory symptoms presumably due to studded tire-generated dust. Environ. Int., 12, 505-511.

12) Kahoku Shimpo (1982) Miyagiken Hyakkajiten (Encyclopedia on Miyagi Prefecture), 582-584, 658 and 1106, Kahoku Shimpo Publishers, Sendai. (Japanese)

13) MacCormac, L., Lew, W., King, G. \& Allen, P.W. (1988) Gynaecological cytology screening in South Australia. Med. J. Aust., 149, 530-536.

14) Ministry of Health and Welfare, the Government of Japan (1974) Health Services in Japan, 52-57, Japan Public Health Association, Tokyo.

15) Ministry of Health and Welfare, the Government of Japan (Department of Senior Health) (1983) Rojin Hoken Ho (Senior Health Act).

16) Ministry of Health and Welfare, the Government of Japan (Department of Senior Health) (1987) Kenko Mappu Suchihyo (Health Map), Kenko-Tairyokuzukuri Zaidan, Tokyo.

17) Miyagi prefecture (Department of Health and Environment) (1985a) Miyagi Eisei Tokei Nenpo (Miyagi Health Statistics) Miyagi prefecture, Sendai.

18) Miyagi prefecture (Department of Health and Environment) (1985b) Miyagi Kanjya Chosa (Miyagi Statistics of Patients), Miyagi prefecture, Sendai.

19) Morris, G.J.A. (1988) Cervical screening: The potential contribution of workplace examinations. Health Bull., 46, 156-159.

20) Morrissey, J.F. (1982) Mass screening for gastric cancer. Gastrointest. Endosc., 28, $112-113$.

21) Murphy, M.F.G., Campbell, M.J. \& Goldblatt, P.O. (1987) Twenty years' screening for cancer of the uterine cervix in Great Britain, 1964-84; further evidence for its ineffectiveness. J. Epidemiol. Community Health, 42, 49-53.

22) Nakatsuka, H., Kasahara, M., Watanabe, T., Hisamichi, S., Shimizu, H., Fujisaku, S., Ichinowatari, Y., Ida, Y., Suda, M., Kato, K. \& Ikeda, M. (1988) Urban-rural difference in food habits: A questionnaire survey in north-eastern Japan. Ecol. Food Nutr., 21, 77-87.

23) Okui, K. \& Tejima, H. (1980) Evaluation of gastric mass survey. Acta Chir. Scand., 146, 185-187.

24) Prime Minister's Office, the Government of Japan (Bureau of Statistics) (1987a) 1985 Kokusei Chosa (1985 Census), Ministry of Finance Printing Bureau, Tokyo.

25) Prime Minister's Office, the Government of Japan (Bureau of Statistics) (1987b) 1987 Shugyo Kozo Kihon Chosa Hokoku Sokuho (1987 Employment Status Survey Short Report), Ministry of Finance Printing Bureau, Tokyo. 
26) Reid, G. (1988) Is there a need for a place-of-work cervical smear service? Health Bull., 46, 153-155.

27) Sato, Y., Nakatsuka, H., Watanabe, T., Hisamichi, S., Shimizu, H., Fujisaku, S., Ichinowatari, Y., Ida, Y., Suda, S., Kato, K. \& Ikeda, M. (1989) Possible contribution of green tea drinking habits to the prevention of stroke. Tohoku J. Exp. Med., 157, 337-343.

28) Shanmugaratnam, K. (1985) Prevention and early detection of cancer. Cancer Detect. Prev., 8, 431-445.

29) Schnieden, H. (1988) District based cervical cancer screening; are there alternative approach? Public Health, 102, 405-406.

30) Shiratori, Y., Nakagawa, S., Kikuchi, A., Ishii, M., Ueno, M., Miyashita, T., Sakurai, T., Negami, J., Suzuki, T. \& Sato, I. (1985) Significance of gastric screening survey. Gastroenterology, 80, 831-834.

31) van der Graaf, Y., Zielhuis, G.A. \& Vooijs, P. (1988) Cervical cancer mortality in the Netherlands. Int. J. Epidemiol., 17, 270-276. 